\title{
Study of maternal mortality in a tertiary care hospital (GMERS- Dharpur, Patan, Gujarat, India): a three-year review
}

\author{
Parul S. Jani* \\ Department of Obstetrics and Gynecology, GMERS Medical College, Patan, Gujarat, India \\ Received: 16 July 2018 \\ Accepted: 28 August 2018 \\ *Correspondence: \\ Dr. Parul S. Jani, \\ E-mail: paruparelia@yahoo.in \\ Copyright: (C) the author(s), publisher and licensee Medip Academy. This is an open-access article distributed under \\ the terms of the Creative Commons Attribution Non-Commercial License, which permits unrestricted non-commercial \\ use, distribution, and reproduction in any medium, provided the original work is properly cited.
}

\begin{abstract}
Background: Epidemiological data related to maternal mortality is valuable in each set up to design the progress to maternal mortality. This study was done to evaluate maternal death over period of 3 years at tertiary care centre of North Gujarat, India.

Methods: This was retrospective study conducted at department of Obstetrics and Gynecology at GMERS medical college Dharpur, Patan (N.G.), India. Epidemiological data was collected from hospital register from January-15 to Dec-17 of maternal death in the hospital maternal age, parity, educational status, ANC registration, mode of delivery, admission death interval and direct and indirect causes and maternal deaths were noted and analyzed statistically.

Results: There were 41 maternal deaths from Jan-15 to Dec-17. Maximum deaths were in 21-30 age group with multipara, unbooked and illiterate patients. Majority of maternal deaths are due to hemorrhage, eclampsia and sepsis.

Conclusions: Many different factors interact in a complex way to increase the risk of death of pregnant women. Regular ANC, early identification of complication and timely referral, delivery by skill birth attendant and adequate post-partum case and follow up are required. To avoid maternal death unwanted pregnancy, too early pregnancy should be avoided adequate counseling and contraception facility also required for sepsis prevention, safe abortion services according to the law and quality post abortion care. There is a wide scope of improvement as most of the maternal deaths are preventable.
\end{abstract}

Keywords: JSSK, Maternal mortality, Maternal mortality ratio, NRHM (National Rural Health Mission)

\section{INTRODUCTION}

Maternal Mortality is a human right issue and an unequivocal expression of the economic, social and cultural disadvantages that women experience. ${ }^{1}$ Most of the maternal deaths occur in developing countries and a large proportion of these deaths are avoidable. ${ }^{2}$ According to World Health Organization(WHO) "A maternal death is define as death of a woman while pregnant or within 42 days of termination of pregnancy, irrespective of the duration and site of pregnancy, from any cause related to or aggravated by pregnancy or its management".(ICD-10). The current maternal mortality ratio of India is 212 per thousand live birth. ${ }^{3}$ Over 6 lakhs maternal deaths occur each year worldwide. ${ }^{4}$ In India, women dies due to pregnancy related complications and those who survives, suffer from sever maternal morbidity. ${ }^{5}$ India contributes the one-fifth of the global burden of absolute maternal deaths. However it has experienced an estimated $4.7 \%$ annual decline in maternal mortality ratio and $3.5 \%$ annual increase in Skill Birth Attendants since $1990 .^{6-8}$ In India, there is marked variation in maternal mortality rate and healthcare assess between regions and in socio economic factors. ${ }^{8}$ The maternal mortality ratio of India has reduced from 212 in 2007 to 167 in $2013 .{ }^{9}$ Various programmes have been 
launched by Government of India to prevent maternal death i.e. JSSK for women and children, a nationwide emergency referral system, maternal death audits, and improvement in Government services at root level also. ${ }^{10}$ NRHM encourages skill birth attendants for partographic labor and timely referral and different skill for postpartum haemorrhage, eclampsia, and sepsis to reduce mortality and morbidity also. This is to achieve the target of sustainable development goal of reducing maternal mortality rate to 70 per one lakh live birth by $2030 .{ }^{11}$

\section{METHODS}

Our hospital is a semi-urban, peripherally situated tertiary care center, in the northern part of Gujarat. We are getting larger number of referral patients from rural parts of north Gujarat and also from Rajasthan. The present study was a retrospective study, conducted in the department of obstetrics and Gynecology of our hospital GMERS medical college- Dharpur, Patan, (N.G.). Data regarding maternal mortality i.e. death of a women while pregnant or within 42 days of termination of pregnancy irrespective of the duration and site of pregnancy-- was collected from the case paper and Annexure 1: Facility Based Maternal Death Review Form of our hospital. The details of total 41 maternal deaths from January 2015 to December 2017 were collected and analyzed with following respect:

- Age wise distribution of maternal deaths,

- Parity wise distribution of maternal deaths,

- Booked status of patients,

- ANC status,

- Direct cause of maternal deaths,

- Indirect causes of maternal death,

- Admission- death interval.

- Those women who died from accidental and incidental causes were not included in the study.

\section{RESULTS}

Table shows maximum number of maternal deaths are in 21-30 year of age. $(85.36 \%)$. Followed by $7.31 \%$ in $31-$ 35 year of age group. And $4.87 \%$ are of more than 35 year of age where as 1 case $(2.43 \%)$ have age less than 20 year.

Table 1: Age wise distribution.

\begin{tabular}{|lll|}
\hline Age (years) & No. & $\%$ \\
\hline$<20$ & 01 & 2.43 \\
\hline $21-25$ & 17 & 41.46 \\
\hline $26-30$ & 18 & 43.90 \\
\hline $31-35$ & 03 & 7.31 \\
\hline$>35$ & 02 & 4.87 \\
\hline
\end{tabular}

In case of parity, maximum number were of multipara $\left(2^{\text {nd }}\right.$ and $3^{\text {rd }}$ and $\left.4^{\text {th }}\right)$. Whereas primi para constitute $26.82 \%$ of present study. Unbooked patients constitute
$68.29 \%$ of present study and $31.70 \%$ were booked patients. Thus, majority of maternal deaths are in unbooked cases.

Table 2: Parity.

\begin{tabular}{|lll|}
\hline Parity & No. & $\%$ \\
\hline Primi & 11 & 26.82 \\
\hline Second & 12 & 29.26 \\
\hline Third & 14 & 34.14 \\
\hline Forth or more & 04 & 9.75 \\
\hline
\end{tabular}

Table 3: Booking status.

\begin{tabular}{|lll|}
\hline Booking Status & No. & $\%$ \\
\hline Booked & 13 & 31.70 \\
\hline Unbooked & 28 & 68.29 \\
\hline
\end{tabular}

Table 4 highlights majority patients of present study were illiterate $(70.73 \%)$ and $29.26 \%$ patients were literate patients.

Table 4: Literacy status.

\begin{tabular}{|lll|}
\hline Literacy status & No. & $\%$ \\
\hline Literate & 12 & 29.26 \\
\hline Illiterate & 29 & 70.73 \\
\hline
\end{tabular}

Comparing the status of the patients at the time of death, $58.53 \%$ if patients had normal vaginal delivery, $19.51 \%$ had LSCS, $14.63 \%$ were ANC, $4.87 \%$ had Abortion, and $1(2.43 \%)$ patient had intra uterine death of baby and delivered. Out of 06 ANC patients, 4 were $\mathrm{H} 1 \mathrm{~N} 1$ positive and 1 was cardiac patient and 1 was having jaundice.

Table 5: Status at the time of death.

\begin{tabular}{|lll|}
\hline Status at time of death & No. & $\%$ \\
\hline Abortion & 02 & 4.87 \\
\hline ANC & 06 & 14.63 \\
\hline Normal vaginal delivery & 24 & 58.53 \\
\hline LSCS & 08 & 19.51 \\
\hline IUD delivery & 01 & 2.43 \\
\hline
\end{tabular}

Table 6 represents that $9(21.95 \%)$ patients were died within 4 hours of hospital admission as they were referred in very late stage, $10(24.39 \%)$ patients were died in 5-24 hours, $12(29.26 \%)$ maternal deaths were in $24-48$ hours of hospital admission and $10(24.39 \%)$ patients were died after 48 hours postpartum.

Table 6: Admission death interval.

\begin{tabular}{|lll|}
\hline Admission death interval (hours) & No. & $\%$ \\
\hline$<4$ & 09 & 21.95 \\
\hline $5-24$ & 10 & 24.39 \\
\hline $24-48$ & 12 & 29.26 \\
\hline$>48$ & 10 & 24.39 \\
\hline
\end{tabular}


Table 7 shows direct causes of maternal deaths in present study. This shows haemorrhage was the leading cause $(26.82 \%)$, followed by ecclamsia and sepsis $(9.75 \%)$ each, and followed by DIC $(9.09 \%)$ and pulmonary embolism (4.54\%).

Table 7: Direct causes.

\begin{tabular}{lll} 
Direct case of maternal mortality & No. & $\%$ \\
Hemorrhage & 11 & 26.82 \\
\hline Eclampsia & 04 & 9.75 \\
\hline Sepsis & 04 & 9.75 \\
DIC & 02 & 9.09 \\
\hline Pulmonary embolism & 01 & 4.54 \\
\hline
\end{tabular}

There were $12(29.26 \%)$ cases of anemia as associated condition, followed by $3(7.31 \%)$ had cardiac disease and $2(4.87 \%)$ cases had jaundice and H1N1 each in present study as shown in Table 8.

Table 8: Associated medical conditions (indirect causes).

\begin{tabular}{|lll|}
\hline Associated medical condition & No. & $\%$ \\
\hline Anemia & 12 & 29.26 \\
\hline Cardiac diseases & 03 & 7.31 \\
\hline Jaundice & 02 & 4.87 \\
\hline H1N1 & 02 & 4.87 \\
\hline
\end{tabular}

\section{DISCUSSION}

Maternal deaths are a significant cause of death in women in the reproductive age group of 15-49 years of age. Further, Maternal mortality is an index of reproductive health of the society. High incidence of maternal deaths reflects poor quality of maternal services, late referral and low socio-economic status of the community. Maternal deaths have been used traditionally as a measure of quality of healthcare in a community. ${ }^{12}$ The current maternal mortality rate of India is $167 / 100000$ live births in2013 which was 212/100000 live births in $2007 .{ }^{9}$ Various studies done in India in last 15 years have shown wide variation in MMR ranging from $47 / 100000$ to $625 / 100000$ births. ${ }^{13-16}$

In present study,75.36\% of maternal deaths were in the age group of 21-30 years, as highest numbers of births are reported in this age group. Similarly, $73.78 \%$ of maternal deaths were reported in multiparous women. More maternal deaths had been reported in unbooked, and illiterate patients. All these findings of present study were similar to studies by Jain, Jadhav, Pal, Onakewhor. ${ }^{13-16}$

In present study, 33 maternal deaths were in postpartum period and 6 patients were undelivered. Similar findings were seen by Khumanthem PD et al. ${ }^{17}$ In their study there was $70 \%$ of maternal deaths were in postpartum period. Regarding Admission death interval, 9 (21.95\%) deaths were in less than 4 hours. This is due to late referral of the patients. Whereas $10(24.39 \%)$ maternal deaths were in another 24 hours, whereas $12(29.26 \%)$ patients died during 24-48 hours of admission. And 10 (24.39\%) maternal deaths were after 48 hours of admission to the hospital. These are consistent with study by Khumanthem et al. ${ }^{17}$

Analyzing the direct cause of maternal mortality in present study, hemorrhage remains the most common cause $(26.82 \%)$ followed by eclampsia $(9.75 \%)$ and sepsis $(9.75 \%)$ and DIC (9.09\%) and pulmonary embolism $(4.54 \%)$. These findings are consistent with study of Jain, Jadhav, Pal, Onakewhor and Shah. ${ }^{14,15,16,18}$ DIC is a consumption coagulopathy and is a key contributor to primary postpartum hemorrhage. About $50 \%$ of patients with DIC are obstetric patients having complications of pregnancy. Because of hypercoaguable state of pregnancy, presence of any provocative factors (such as abruption placenta, liquor amnii embolism, sepsis, severe eclampsia and HELLP syndrome) can be easily upset normal balance leading to DIC. ${ }^{19}$ All these are preventable causes of maternal mortality provided the treatment is started promptly. Unfortunately, in many cases, patients were referred very late, in critical conditions, unaccompanied by healthcare worker. Many patients had to travel a distance of 70-80 kilometer in a private vehicle to reach a tertiary care center. Most of these deaths are preventable if timely referral is done and treatment is started promptly. Training of Medical Officer (BEMOC) and Skill Birth Attendant gives a ray to reduce Maternal Mortality.

Analyzing the Indirect causes of maternal deaths in present study, Anemia was in $12(29.26 \%)$ of maternal deaths, cardiac disease was in $3(7.31 \%)$, and jaundice was in $2(4.87 \%)$ cases. These are consistent with studies of Jain, Jadhav, Pal, Onakewhor. ${ }^{13-16}$ Anemia is the major indirect cause of death responsible for $15-65 \%$ of deaths reported by various authors. ${ }^{20,21}$ Anemia is a preventable disease and measures should be taken to improve status pre-conceptionally and during pregnancy. Cardiac diseases are the other major indirect cause of maternal mortality. Jaundice is the second major indirect cause of maternal death. Hepatitis $\mathrm{E}$ is responsible for $8.33 \%$ of total maternal deaths. It can lead to fulminating hepatitis during pregnancy and leads to maternal morbidity and mortality. Present finding is consistent with study by Patra S et al. ${ }^{22}$

\section{CONCLUSION}

Maternal deaths are not only a health issue but also a matter of injustice. Maternal death is a measure of quality of healthcare in community. Many different factors interact in a complex way to increase pregnant women risk of death. There is a wide scope of improvement as a large proportion of the maternal deaths are preventable. Even today, most maternal deaths are seen in patients from rural areas, unbooked, illiterate patients and patients from low socioeconomic class. Haemorrhage remains the 
leading cause of death followed by eclampsia and sepsis. The death of a woman has a lifelong implication for children and family left behind, not to mention community and the nation. Although we may not be able to prevent all deaths and morbidity, we need to proactively address "preventable" events. Maternal deaths can be prevented by improvement in public health care system in rural areas, proper implementation of NRHM programmes and up gradation of hospitals in rural areas.

Funding: No funding sources Conflict of interest: None declared

Ethical approval: The study was approved by the Institutional Ethics Committee

\section{REFERENCES}

1. United Nations. The Universal declaration of human rights. New York: United Nations; 1948. Available at: http//www.un.org/Overview/rights.html.

2. Ronsmas C, Graham WJ. Lancet Maternal Survival Series group. Maternal Mortality: who, when, where, and why. Lanet. 2006;368(9542):1189-200.

3. 3) Special Bulletin on Maternal Mortality in India 2007-09: Sample Registration System, Office of Registrar General, India.2011 Jun. Available at http://censusindia.gov.in/Vital_Statistics/SRS_Bullet ins/Final-MMR\%20Bulletin-2007-09_070711.pdf

4. Mc Clure EM, Goldenberg RL, Bann CM. Maternal mortality, stillbirth and measures of obstetric care in developing and developed countries. Int J Gynecol Obstet. 2007;96(2):139-46.

5. Khosla AH, Mehara R, Dua D, Gupta P. Maternal morbidity and Mortality: an assessment of prevalence and aietiological factors. Obs Gynae Today 2006;11:447-9.

6. RGI (2006) Registrar General/centre for Global Health research, University of Toronto, New Delhi: Registrar General of India. Available at http://cghr.org/wordpress/wpcontent/uploads/2011/07/MDS-Study-Protocol.pdf

7. WHO, UNICEF, UNFPA, World Bank (2012) Trends in Maternal Morality: 1990 to 2010Geneva: World Health Organization. Available at http://www.who.int/reproductivehealth/publications/ monitoring/9789241503631/en/

8. IIPS (2010) District level household and facility survey (DLHS-3) 2007-2008: India, Mumbai: International Institute for Population Science. Available at http://rchiips.org/pdf/INDIA_REPORT_DLHS-3.pdf

9. Special Bulletin on Maternal Mortality. Government of India. Available at http//www.censusindia.gov.in/vital statistics/SRS Bulletins/MMR-Bulletin-2010-12.pdf.

10. National Rural Health Mission: Framework for implementation 2005-2012; New Delhi: Ministry of Health and Family Welfare, Government of India. Available at: nrhm.gov.in/nhm/nrhm-framework-forimplimentation.html.

11. UN Sustainable Development Goals. Available at: http//www.un.org./sustainabledevelopment/health/.

12. Kaul V, Bagga R, Jain V, Gopalan S. The impact of primary postpartum haemorrhage in "near-miss" morbidity and mortality in a tertiary care hospital in North India. Indian J Med Sci. 2006,60:233-40.

13. Jain M, Maharahaje S. Maternal mortality: A retrospective analysis of 10 years in a tertiary hospital. Indian J Prev Soc Med. 2003;34(3-4):10311.

14. Jadhav AJ,Rote PG, Maternal mortality-changing trends. J Obstet Gynecol India. 2007:57(5):398-400.

15. Pal A, Ray P, Hazra S, Mondal TK. Review of changing trends in Maternal Mortality in a rural medical college in West Bengal. J Obstet Gynecol India, 2005:55(6):521-4.

16. Onkewhor JU, Gharoro EP. Changing trends in Maternal Mortality in a developing country. Niger $\mathbf{J}$ Clin Pract. 2008;11(2):111-20.

17. Khumanthem PD, Chanam MS, Samjetshabam RD. Maternal mortality and its causes in a tertiary centre: J Obstet Gynecol India.2012;62(2):168-71.

18. Shah RJ, AliI, Banday A, Fazili A, Khan I. Analysis of maternal mortality in a small teaching hospital attached to tertiary care hospital. Indian $\mathbf{J}$ Community Med. 2008;33(4):260-2.

19. Patel A, Shukla D, Hazara M. Retained placenta;the third stage threat(12 years study). J Obstet Gynecol India. 1991;41:606-10.

20. Sharma S, Aherwar R, Jawade S, Maternal and fetal outcome in jaundice complicating pregnancy: A prospective study. Int. J Reprod Contracept Obstet Gynecol. 2016;5(4):1084-7.

21. Pal SJ, Rao MA, A three year review of maternal mortality in a district hospital on the west coast in south India( April 2011-2014). Int J Innov Res Dev. 2014;3(7):15-21.

22. Patra S, Kumari A, Trivedi SS, Puri M, Sarin SK. Maternal and fetal outcome in pregnant women with acute hepatitis $\mathrm{E}$ virus. Ann Intern Med. 2007;147(1):28-33.

Cite this article as: Jani SP. Study of maternal mortality in a tertiary care hospital (GMERSDharpur, Patan, Gujarat, India): a three-year review. Int J Reprod Contracept Obstet Gynecol 2018;7:4008-11. 